\title{
DESENVOLVIMENTO DE PROCESSO DE PURIFICAÇÃO DA PROTEÍNA A DE SUPERFÍCIE DO PNEUMOCOCO DO CLADO 4 (PspA4pro)
}

\author{
D. B. FIGUEIREDO ${ }^{1}$, E. CARVALHO ${ }^{1}$, S. KRASCHOWETZ1, R. T. ZANARDO ${ }^{1}$, \\ G.G. SILVA ${ }^{2}$, G. CAMPANI ${ }^{2}$, T. C. ZANGIROLAMI ${ }^{2}$, J. CABRERA-CRESPO ${ }^{1}$, V. \\ M. GONÇALVES ${ }^{1}$ \\ ${ }^{1}$ Instituto Butantan, Centro de Biotecnologia, ${ }^{2}$ Universidade Federal de São Carlos, \\ Departamento de Engenharia Química
}

E-mail para contato: douglas.figueiredo@usp.br

\begin{abstract}
RESUMO: S. pneumoniae provoca doenças com elevada mortalidade infantil como pneumonia, meningite e sepse, assim buscam-se vacinas alternativas mais eficazes. Neste trabalho desenvolveu-se um processo escalonável de purificação do fragmento recombinante da PspA do clado 4 para uso em uma nova vacina, que consistiu das etapas: ruptura celular em homogeneizador contínuo de alta pressão, precipitação com detergente $\mathrm{CTAB}$, clarificação, cromatografia de troca aniônica, crioprecipitação a pH4,0 e cromatografia de troca catiônica. PspA4Pro foi obtida com pureza $>97 \%$ e recuperação de 30\%. A eliminação final do lipopolissacarídeo (contaminante que causa febre) foi feita em resina de polilisina. Espectros de dicroísmo circular mostraram estrutura secundária correta da PspA4Pro purificada, bem como estabilidade térmica e a variações de $\mathrm{pH}$. A atividade de PspA4Pro foi confirmada em ensaio de ligação à lactoferrina. Portanto, o processo é adequado à obtenção de PspA4Pro com as características requeridas para uso humano.
\end{abstract}

\section{INTRODUÇÃO}

Dentre os antígenos proteicos candidatos ao uso em vacinas pneumocócicas, a proteína A de superfície do pneumococo (PspA) tem se mostrado bastante promissora, principalmente por ser uma proteína exposta externamente à capsula polissacarídica. A estrutura da PspA é composta por quatro domínios. A porção N-terminal é bastante carregada eletricamente e apresenta estrutura secundária predominantemente do tipo $\alpha$-hélice "coiled-coil". Esta porção se projeta para fora da superfície do microrganismo e nela encontra-se a região definidora de clado. Em seguida há um domínio flexível rico em prolinas. A ele segue-se um domínio com 10 repetições de uma sequência de 20 aminoácidos, responsável pela ligação à colina, ancorando a proteína aos resíduos de colina encontrados nos ácidos teicóico e lipoteicóico da parede celular. A porção Cterminal é composta por uma cauda hidrofóbica (Briles, et al., 1997).

Com base na homologia e no alinhamento das sequências de aminoácidos de PspA de diferentes cepas de $S$. pneumoniae, foram observadas 3 famílias distintas desta proteína, as quais podem ser divididas em 6 grupos, denominados clados. A família 1 da PspA é constituída por dois clados: 1 e 2, a família 2, por três clados: 3, 4 e 5 e a família 3, por apenas um clado: 6 (Bogaert et al. , 2003). As famílias 1 e 2, em especial os clados 1 a 4, são predominantes no 


\section{9 a 22 de outubro de 2014 \\ Florianópolis/SC}

mundo todo e no Brasil estão presentes em 99\% dos isolados clínicos (Mantese et al., 2003). Uma vez que proteínas dentro de uma mesma família apresentam reação imunológica cruzada, acredita-se que apenas duas proteínas, uma da família 1 e outra da família 2, seriam suficientes para compor uma vacina com boa cobertura das cepas de pneumococo circulantes na população

\section{OBJETIVOS}

Desenvolver um processo de purificação para obter a proteína PspA4Pro, produzida por cultivo de E. coli recombinante, com pureza superior a 95\% com relação às demais proteínas, para uso em vacinas pneumocócicas tanto de proteínas puras como conjugadas a polissacarídeos.

\section{MATERIAIS E MÉTODOS}

\subsection{Material de partida}

Devido às características antigênicas, o fragmento de PspA do clado 4 clonado contém a porção N-terminal, a região definidora de clado e a primeira parte da região rica em prolina da molécula (PspA4Pro) e foi desenvolvido pela equipe da Dra. Eliane N. Miyiaji, que gentilmente cedeu a cepa de E. coli transformada para a realização deste trabalho (Moreno, et al. , 2010) A proteína foi produzida na forma solúvel em E. coli BL21(DE3) empregando o plasmídeo pET37b+. Os cultivos foram centrifugados e o pellet foi congelado a $-80^{\circ} \mathrm{C}$ até o uso.

\subsection{Ruptura celular}

$100 \mathrm{~g}$ de pellet congelado foram ressuspendidos em 1 litro de tampão de lise: tampão $\mathrm{NaH}_{2} \mathrm{PO}_{4} 10 \mathrm{mM}$ pH6,5 + EDTA 2,5mM com $0,1 \%(\mathrm{p} / \mathrm{v})$ do detergente Triton X-100 e $1 \mathrm{mM}$ do inibidor de proteases Phenylmethilsulfonyl Fluoride (PMSF). A ressuspensão foi realizada a aproximadamente $4^{\circ} \mathrm{C}$, utilizando um homogeneizador de pás a $11.000 \mathrm{rpm}$ do modelo X-520 (Ingenieurbüro CAT M. Zipperer $\mathrm{GmbH}$ ), até não haver mais grumos visíveis. Esta suspensão bacteriana foi colocada em um funil encamisado acoplado ao homogeneizador contínuo de alta pressão (APV GAULIN) com a saída também refrigerada por meio de um trocador de calor do tipo casco e tubo. A temperatura do refrigerante foi ajustada para $4^{\circ} \mathrm{C}$ e a pressão de trabalho foi de 500bar com fluxo de amostra de $1 \mathrm{~L} / \mathrm{min}$. A amostra foi recirculada em loop fechado até todo o volume passar pelo menos seis vezes pelo homogeneizador e ao final foi empurrada com $500 \mathrm{~mL}$ de tampão de lise. A fração recolhida do homogeneizador foi nomeada Homogenato.

\subsection{Clarificação}

O Homogenato foi precipitado com uma solução $10 \%$ do detergente catiônico brometo de cetiltrimetilamônio (CTAB), adicionado até a concentração de $0,085 \%$ (p/v). Após a adição do detergente o Homogenato permaneceu sob agitação por 90 min para então ser centrifugado $\left(17696 \mathrm{~g}, 120 \mathrm{~min}, 4^{\circ} \mathrm{C}\right)$. O pellet foi descartado e o sobrenadante, chamado Clarificado, seguiu para as etapas cromatográficas.

\subsection{Cromatografia de troca aniônica em Q-Sepharose}

A cromatografia de troca aniônica foi realizada em resina Q-Sepharose Fast Flow empacotada em coluna XK 50/30 (diâmetro $(\varnothing)=50 \mathrm{~mm}$ e altura do leito cromatográfico $(\mathrm{Lc})=$ 
$13 \mathrm{~cm}$ ) acoplada a um cromatógrafo BioPilot, Äkta Explorer, ou Äkta Avant (GE Lifescience). O volume de coluna (VC) foi de $250 \mathrm{~mL}$ e o fluxo de trabalho foi de $50 \mathrm{~mL} / \mathrm{min}$. A resina foi equilibrada com $5 \mathrm{VC}$ de uma solução de fosfato de sódio $10 \mathrm{mM}$ pH6,5 (condutividade de $1,2 \mathrm{mS} / \mathrm{cm}$ ) e lavada com $5 \mathrm{VC}$ da mesma solução após a aplicação da amostra. A eluição foi feita com um gradiente descontínuo e crescente de $\mathrm{NaCl}(150 \mathrm{mM}, 300 \mathrm{mM}$ e $1000 \mathrm{mM})$ em fosfato-Na $15 \mathrm{mM}$ pH6,5 e sempre com $5 \mathrm{VC}$ para cada fração. A resina foi regenerada com $3 \mathrm{VC}$ de solução de $\mathrm{NaOH} 100 \mathrm{mM}$. As amostras aplicadas à resina tiveram o pH ajustado para $6,5 \mathrm{e}$ a condutividade para aproximadamente $1,5 \mathrm{mS} / \mathrm{cm}$. A fração não adsorvida foi chamada $\mathrm{F} 1 \mathrm{Q}$ e as frações eluídas foram chamadas de $\mathrm{Qx}$ (onde $\mathrm{x}=$ concentração de $\mathrm{NaCl}$ na eluição em $\mathrm{mM}$ ).

\subsection{Crioprecipitação a pH4,0}

Para ser aplicada na resina de troca catiônica, a fração eluída da Q-sepharose teve seu $\mathrm{pH}$ reduzido para 4,0 com ácido acético glacial e foi congelado $\left(-20^{\circ} \mathrm{C}\right)$ por pelo menos 24 horas. A amostra foi descongelada e centrifugada $\left(17696 \mathrm{~g}, 60 \mathrm{~min}, 4^{\circ} \mathrm{C}\right)$ e o sobrenadante, denominado Crio-pH4,0, foi aplicado na resina SP-Sepharose.

\subsection{Cromatografia de troca catiônica em SP-Sepharose}

A cromatografia de troca catiônica foi realizada com resina SP-Sepharose 6 Fast Flow empacotada em coluna XK 26/20 ( $\varnothing=26 \mathrm{~mm}, \mathrm{Lc}=14 \mathrm{~cm}, \mathrm{VC}=75 \mathrm{~mL}$, fluxo $=12 \mathrm{~mL} / \mathrm{min}) . \mathrm{O}$ sistema de controle da cromatografia foi o mesmo utilizado na Q-Sepharose. A resina foi equilibrada com $5 \mathrm{VC}$ de uma solução de acetato-Na $25 \mathrm{mMpH} 4,0(5 \mathrm{mS} / \mathrm{cm})$ e lavada com $5 \mathrm{VC}$ da mesma solução após a aplicação da amostra. As eluições foram feitas com um gradiente descontínuo e crescente de $\mathrm{NaCl}$ em acetato- $\mathrm{Na}$ pH4, $0(500 \mathrm{mM}$ e $650 \mathrm{mM})$ e em $1000 \mathrm{mM} \mathrm{NaCl}$ em acetato-Na pH6,5. A regeneração foi feita com $3 \mathrm{VC}$ de uma solução de $\mathrm{NaOH} 100 \mathrm{mM}$. As amostras aplicadas à resina tiveram a condutividade ajustada para aproximadamente $20 \mathrm{mS} / \mathrm{cm}$ com água destilada e o pH reajustado para 4,0 com ácido acético glacial.

\subsection{Atividade da PspA4Pro após a purificação.}

A atividade da PspA4Pro foi verificada por teste de ligação à lactoferrina humana (SigmaAldrich). As proteínas foram misturadas em três diferentes proporções de modo a obter-se as seguintes quantidades: $2 \mathrm{mg}$ de PspA4Pro $+0,5 \mathrm{mg}$ de lactoferrina, $1 \mathrm{mg}$ de PspA4Pro $+1 \mathrm{mg}$ de lactoferrina e $1 \mathrm{mg}$ de PspA4Pro $+2 \mathrm{mg}$ de lactoferrina. As amostras foram incubadas a $37^{\circ} \mathrm{C}$ por $1 \mathrm{~h}$ e foram aplicadas a uma coluna de gel filtração TSK-GEL G2000SWXL (Tosoh Bioscience) acoplada a um equipamento para cromatografia líquida de alta eficiência (CLAE) SCL-10AVP (Shimadzu). A fase móvel utilizada foi fosfato de sódio $500 \mathrm{mM} \mathrm{pH7,0} \mathrm{com} 300 \mathrm{mM} \mathrm{NaCl}$, o fluxo de $0,6 \mathrm{~mL} / \mathrm{min}$ e detector de UV280nm.

\subsection{Métodos analíticos}

A concentração proteica foi medida por Lowry empregando albumina do soro bovino como padrão (Lowry, et al, 1951). A pureza relativa foi determinada por densitometria (densitômetro Bio-Rad GS-800) dos géis de SDS-PAGE a 12\% contendo 2-mercaptoetanol (Laemmli, 1970). A pureza foi calculada como a porcentagem da banda correspondente à PspA4Pro em relação à soma das densidades das demais bandas na respectiva caneleta do gel. 


\subsection{Estrutura secundária e estabilidade da PspA4Pro após a purificação.}

A estrutura secundária e a estabilidade foram avaliadas por dicroísmo circular em espectropolarímetro Jasco J-180 (Japan Spectroscopic, Tokyo, Japan) equipado com uma unidade Peltier para controle de temperatura. Para obtenção dos espectros, a PspA4Pro purificada foi dialisada contra tampão fosfato $10 \mathrm{mM} \mathrm{pH} \mathrm{7,0} \mathrm{por} 18 \mathrm{~h}$ com 4 trocas de tampão. A concentração após a diálise foi determinada por Bradford (Bradford, 1976). A estabilidade em presença de CTAB foi avaliada acrescentando-se CTAB $0,15 \%$ à amostra dialisada antes da aquisição do espectro. Para avaliação da estabilidade térmica, a amostra foi aquecida a $1^{\circ} \mathrm{C} / \mathrm{min}$ até $95^{\circ} \mathrm{e}$ depois resfriada até $15^{\circ} \mathrm{C}$ na mesma velocidade. Para avaliar a estabilidade ao $\mathrm{pH}$, as amostras tiveram seu pH ajustado de 4,0 a 9,0 antes da obtenção dos espectros e a concentração proteica em cada $\mathrm{pH}$ foi determinada por Bradford.

\subsection{Remoção de endotoxina}

O lipopolissacarídeo (LPS), ou endotoxina, ainda presente na PspA4Pro purificada foi removido utilizando um kit de remoção de endotoxina (Pierce Thermo Science) contendo $1 \mathrm{~mL}$ de resina de poli- $\varepsilon$-L-lisina em tubo falcon de $10 \mathrm{~mL}$. A concentração final de endotoxina foi medida por teste de Limulus Amebocyte lysate (LAL), gentilmente realizado por Bianca Pereira Carvalho, da Seção de Vacina Aeróbicas do Instituto Butantan.

\section{RESULTADOS E DISCUSSÃO}

A Figura mostra o perfil de ruptura celular. A queda da D0600nm, que indica a concentração celular, atingiu o platô aos $4 \mathrm{~min}$ e a Abs280nm apresentou ligeiro incremento até o final do processo. Apesar de a temperatura ter aumentado de $15^{\circ} \mathrm{C}$ para $23,7^{\circ} \mathrm{C}$ ao longo do processo, isso não chegou a oferecer risco de desnaturação da PspA4Pro, como será mostrado adiante.

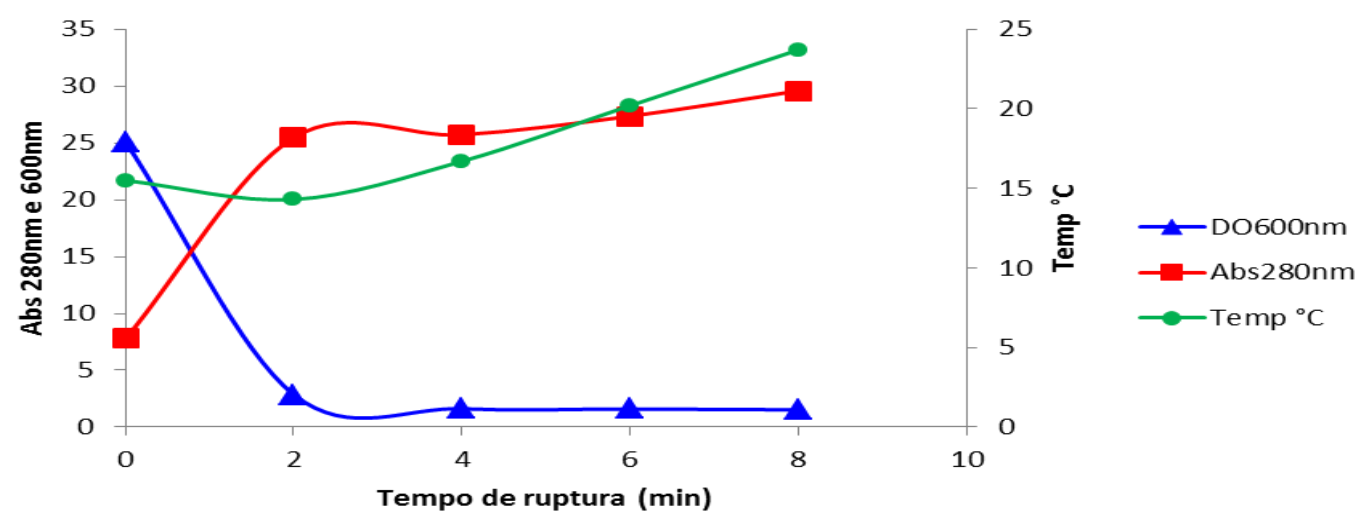

Figura 1. Acompanhamento da ruptura celular (DO 600nm), extração de proteínas (Abs 280nm) e temperatura no processo de purificação.

Como mostra a Tabela 1, a cromatografia de troca aniônica foi a etapa que mais contribuiu para a pureza da PspA4Pro (fator de purificação $(\mathrm{FP})=1,73$ ) com recuperação de $87,1 \%$. Na cromatografia de troca catiônica, a PspA4Pro foi eluída em duas frações com $\mathrm{NaCl} 1 \mathrm{M}$ a pH4,0 e a pH6,5. Na primeira, a pureza foi de $98,5 \%$ e a recuperação de $31 \%$, enquanto na segunda a pureza foi de $96,9 \%$ e a recuperação de $58 \%$. Juntando as duas frações, a recuperação final deste 


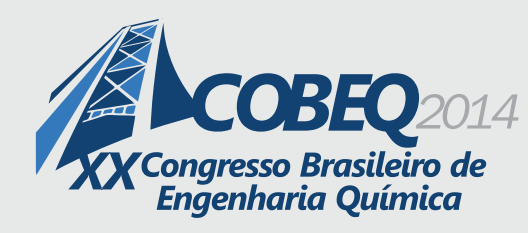

19 a 22 de outubro de 2014

Florianópolis/SC

processo foi de $33 \%$. Embora o ideal seja recuperar a proteína de interesse em uma única fração para não aumentar o volume, como ambas as frações atingiram a pureza requerida, ambas foram reunidas e consideradas no cálculo de recuperação final.

Tabela 1. Avaliação do processo de processo de purificação

\begin{tabular}{|c|c|c|c|c|c|c|}
\hline Fração & $\begin{array}{c}\text { Pureza } \\
\text { PspA4Pro } \\
(\%)\end{array}$ & $\begin{array}{c}\text { PspA4 } \\
\text { total (g) }\end{array}$ & $\begin{array}{c}\text { Recuperação } \\
\text { geral } \\
\text { PspA4Pro (\%) }\end{array}$ & $\begin{array}{c}\text { Recuperação } \\
\text { por etapa } \\
\text { PspA4Pro (\%) }\end{array}$ & $\begin{array}{c}\text { Fator de } \\
\text { Purificação } \\
\text { geral (Vezes) }\end{array}$ & $\begin{array}{c}\text { Fator de } \\
\text { Purificação por } \\
\text { etapa (Vezes) }\end{array}$ \\
\hline Homogenato & 33,3 & 2,5 & 100 & 100 & 1 & 1 \\
\hline $\begin{array}{c}\text { Clarificado CTAB } \\
0,085 \%\end{array}$ & 44,1 & 1,9 & 77,0 & 77,0 & 1,32 & 1,32 \\
\hline Q300 & 76,3 & 1,7 & 67,0 & 87,1 & 2,29 & 1,73 \\
\hline Crio + pH4,0 & 88,2 & 0,9 & 37,4 & 55,9 & 2,65 & 1,16 \\
\hline SP1000 pH4,0 & 98,5 & 0,3 & 11,6 & 31,0 & 2,96 & 1,12 \\
\hline SP1000 pH6,5 & 96,9 & 0,5 & 21,9 & 58,4 & 2,91 & 1,10 \\
\hline
\end{tabular}

Na Figura 2A observa-se o cromatograma da PspA4Pro purificada, ou seja, o pool das frações SP1000 (tempo de retenção (TR) de 12,85 min) e o da lactoferrina pura (TR = 15,03 $\mathrm{min}$ ). Após a mistura das duas (Figura 2B), nota-se em vermelho o surgimento de um novo pico correspondente às duas proteínas ligadas $(\mathrm{TR}=12,558 \mathrm{~min})$ e um segundo pico correspondente ao excesso de PspA4Pro (TR = 13,050 min). Aumentando a concentração de lactoferrina percebese uma transição para um pico único em verde, $\mathrm{TR}=12,692 \mathrm{~min}$, indicando somente proteínas ligadas, e novamente dois picos em azul escuro, quando há excesso de lactoferrina (TR = 15,283 min). É importante ressaltar que o fragmento recombinante obtido manteve a capacidade de ligação à lactoferrina mesmo em condições de elevada força iônica, uma vez que a fase móvel continha $300 \mathrm{mM}$ de $\mathrm{NaCl}$ e $500 \mathrm{mM}$ de fosfato de sódio, o que indica que o processo de purificação não afetou a atividade da PspA4Pro.

A Figura 3 mostra os espectros de dicroísmo circular da PspA4Pro em tampão fosfato de sódio $10 \mathrm{mM}$ pH7,0 e em tampão fosfato de sódio $10 \mathrm{mM}$ pH7,0 com CTAB 0,15\%. Neste último caso não foi possível obter o espectro abaixo de $200 \mathrm{~nm}$ devido à elevada absorção de luz pelo CTAB nessa faixa de comprimento de onda.

Observou-se que o maior vale na medida da elipticidade molar ocorreu entre 210 e $223 \mathrm{~nm}$, comprimentos de onda referentes à $\alpha$-hélice. Este resultado condiz com a estrutura secundária esperada para o fragmento de PspA4Pro recombinante obtido, que contém a região rica em $\alpha$-hélice da porção N-terminal e a primeira porção da região rica em prolinas.

O aumento da elipticidade molar entre 200 e 240nm indica perda da estrutura da PspA4Pro quando em tampão contendo CTAB. Esta perda, contudo, foi reversível, uma vez que a PspA4Pro purificada já passou por uma etapa de precipitação em CTAB durante a clarificação. Ou seja, a proteína recuperou sua estrutura secundária característica de $\alpha$-hélice após a retirada do CTAB ao longo do processo de purificação. Este resultado levou à hipótese de que a perda de estrutura da PspA4Pro em presença de CTAB poderia favorecer sua agregação com outras 
moléculas do Homogenato durante a clarificação, o que poderia explicar a recuperação relativamente baixa desta etapa $(77 \%$, Tabela 1$)$.
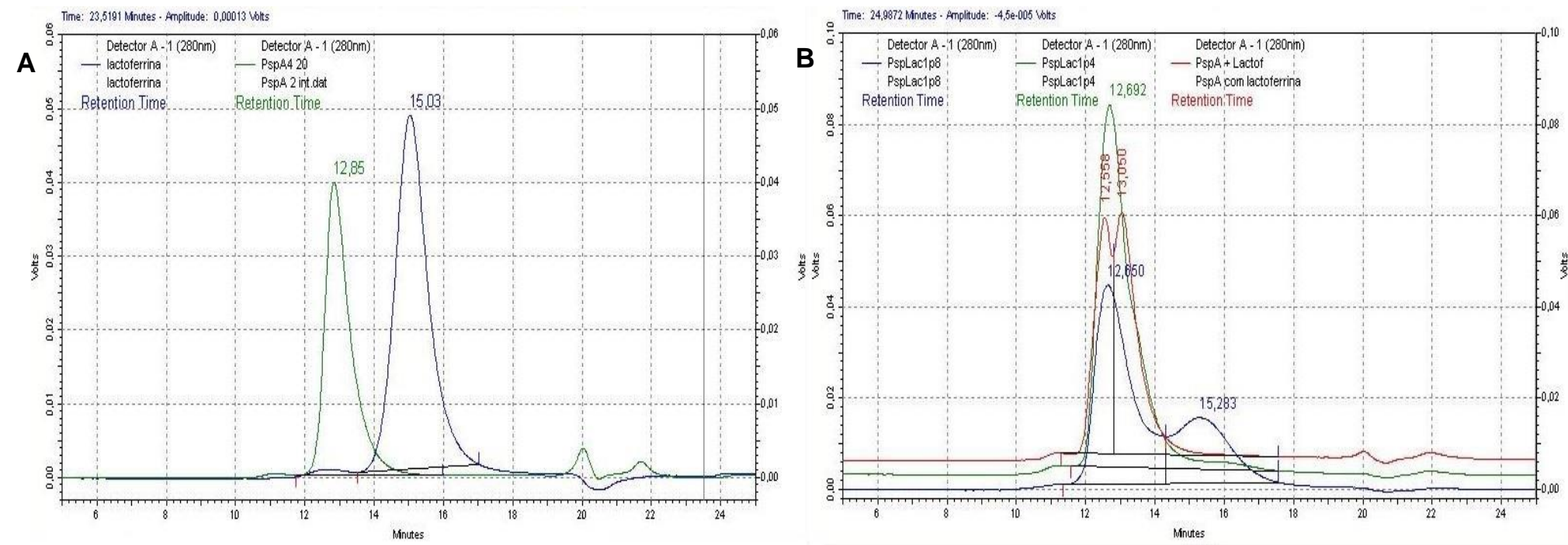

Figura 2: Avaliação da ligação de PspA4Pro à lactoferrina por CLAE. A) $2 \mathrm{mg} / \mathrm{mL}$ PspA4Pro pura (verde) e 1mg/mL Lactoferrina (azul escuro); B) 2mg PspA4Pro + 0,5mg Lactoferrina (vermelho), 1mg PspA4Pro + 1mg Lactoferrina (verde), 1mg PspA4Pro + 2mg Lactoferrina (azul escuro).

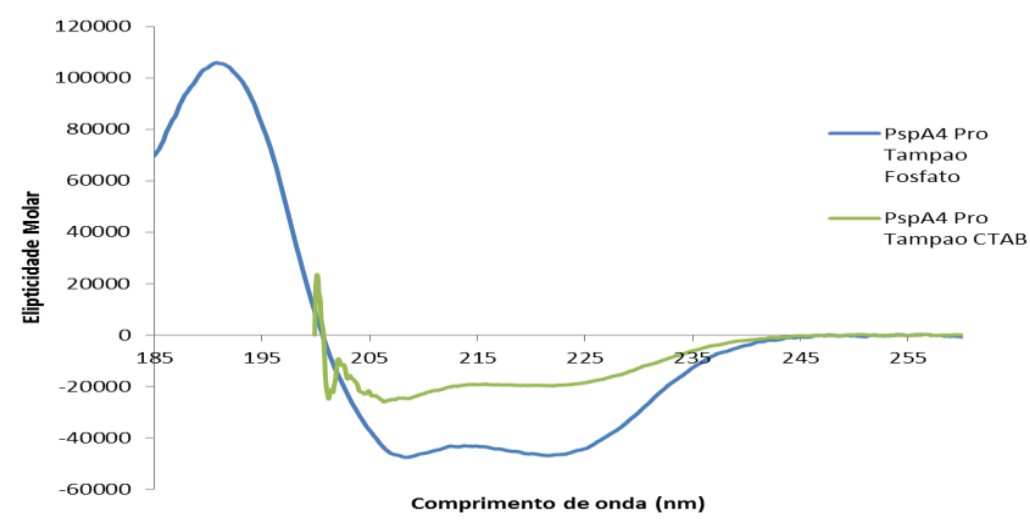

Figura 3: Espectros de dicroísmo circular da PspA4Pro na presença (verde) e ausência (azul) de CTAB.

A Figura 4 compara a elipticidade molar de uma amostra de PspA4Pro aquecida a $95^{\circ} \mathrm{C}$ e posteriormente resfriada, com a elipticidade de uma amostra que não passou pelo aquecimento. A sobreposição das curvas na Figura 4 indica que o aquecimento da PspA4Pro não provocou a perda irreversível da estrutura secundária da proteína, ou seja, a PspA4Pro é relativamente estável termicamente. 


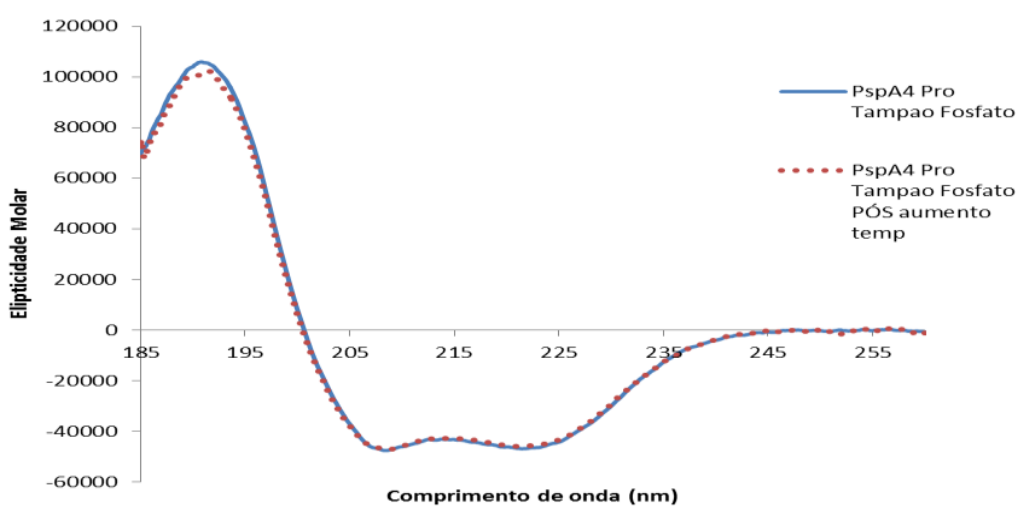

Figura 4: Espectros de dicroísmo circular da PspA4Pro sem tratamento térmico (azul) e após aquecimento até $95^{\circ} \mathrm{C}\left(1^{\circ} \mathrm{C} / \mathrm{min}\right)$ e resfriamento até $15^{\circ} \mathrm{C}$ (em vermelho pontilhado).

Observou-se ainda que a proteína conservou melhor sua estrutura secundária em $\mathrm{pH}$ ácidos, com as maiores perdas de estrutura ocorrendo em $\mathrm{pH}$ 8,5 e 9,0 (Figura 5). A proteína apresentou maior conteúdo de $\alpha$-hélice em $\mathrm{pH} 5,0$, valor próximo ao seu $\mathrm{pI}(4,8)$. A elipticidade em $\mathrm{pH} 4,0$, que foi o menor valor de $\mathrm{pH}$ utilizado durante o processo de purificação, foi semelhante àquela dos $\mathrm{pH}$ próximos à neutralidade, indicando que as etapas de crioprecipitação a pH 4,0 e cromatografia de troca catiônica não devem ter afetado a estrutura secundária da proteína.

Após a aplicação da PspA4Pro purificada à resina de poli- $\varepsilon$-L-lisina, a concentração de LPS foi reduzida de $3,1 \mathrm{EU} / \mathrm{mg}$ de proteína para $0,6 \mathrm{EU} / \mathrm{mg}$. A passagem da proteína pela resina reduziu em $80 \%$ a concentração de endotoxina por miligrama de proteína, atingindo a concentração similar à exigida para outras vacinas de uso humano (<1EU/mg) (European Pharmacopoeia, 2005).

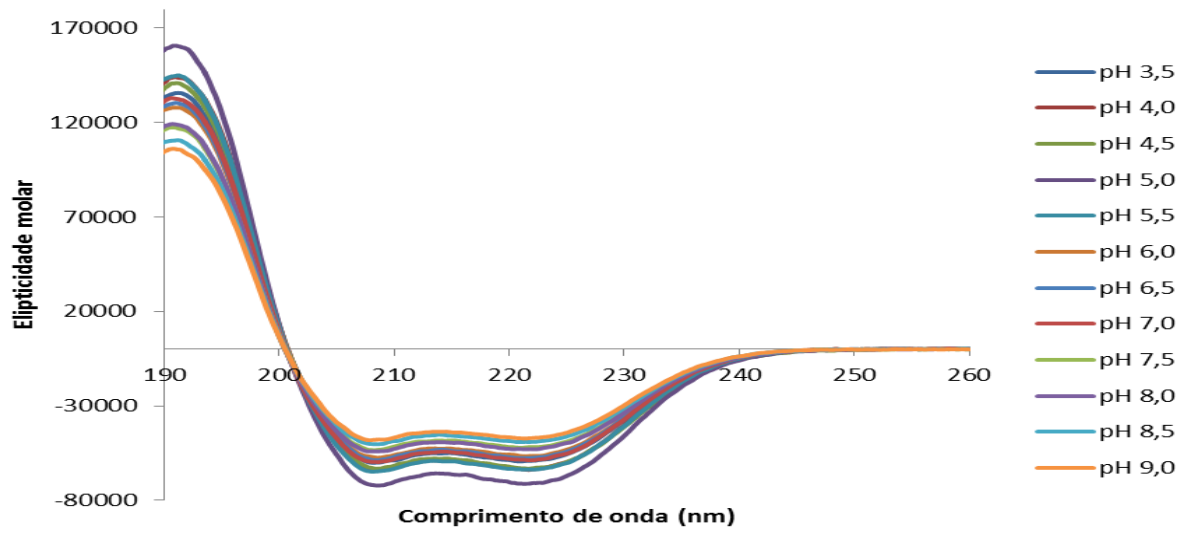

Figura 5: Espectros de dicroísmo circular da PspA4Pro em diferentes valos de $\mathrm{pH}$. 


\section{CONCLUSÃO}

O processo de purificação desenvolvido possibilitou a obtenção de PspA4Pro com a pureza requerida e baixa concentração de LPS. A precipitação com CTAB e a cromatografia de troca aniônica foram as etapas que mais contribuíram para o aumento da pureza. Estudos adicionais são necessários para estabelecer a condição adequada para eluir a PspA4Pro em uma única fração na cromatografia de troca catiônica. O processo de purificação não alterou a estrutura secundária da PspA4Pro, que manteve sua capacidade de ligação à lactoferrina.

\section{REFERÊNCIAS BIBLIOGRÁFICAS}

BOGAERT, D.; HERMANS, P.W.M.; ADRIAN, P.V.; RUMKE, H.C.; DE GROOT, R.; Pneumococcal vaccines: an update on current strategies. Vaccine v. 22, p. 2209-2220, 2003

BRADFORD, M.M., Rapid and sensitive method for the quantitation of microgram quantities of protein utilizing the principle of protein-dye binding, Anal. Biochem. v.72, p. 248-254, 1976

BRILES, D.E.; HOLLINSHED, S.; SWIATLO, E.; BROOKS-WALTER, A. et al. PspA and PspC: their potential for use as pneumococcal vaccines. Microbial Drug Resistance, v. 3, p. 401-408,1997.

EUROPEAN PHARMACOPOEIA, 5ª ed. v. 1, p. 161-168, 662 - 664, 2005.

LAEMMLI, U.K.; Cleavage of Structural Proteins During the Assembly of the Head of Bacteriophage T4. Nature. v.227, p682-685, 1970.

LOWRY, O. H.; ROSENBROUGH, N. J.; FARR, R. H. Protein measurement with Folin phenol reagent. J. Biol. Chem., v.193, p.265-275, 1951.

MANTESE. O,C.; PAULA, A.; MORAES, A.B.; MOREIRA, T.A.; GUERRA, M.L.L.S. BRANDILEONE, M.C.C.; Prevalência de sorotipos e resistência antimicrobiana de cepas invasivas do Streptococcus pneumoniae. J.Pediatria, v. 79, p. 537-42, 2003.

MORENO, A. T., OLIVEIRA, M. L. S., FERREIRA,, D. M., HO, P. L., DARRIEUX, M., LEITE, L. C. C., FERREIRA, J. M. C., PIMENTA, F. C., ANDRADE, A. L. S. S., MIYAJI, E. N. Immunization of Mice with Single PspA Fragments Induces Antibodies Capable of Mediating Complement Deposition on Different Pneumococcal Strains and Cross-Protection. Clinical and Vaccine Immunology. v.17, p. 439-446. 2010. 